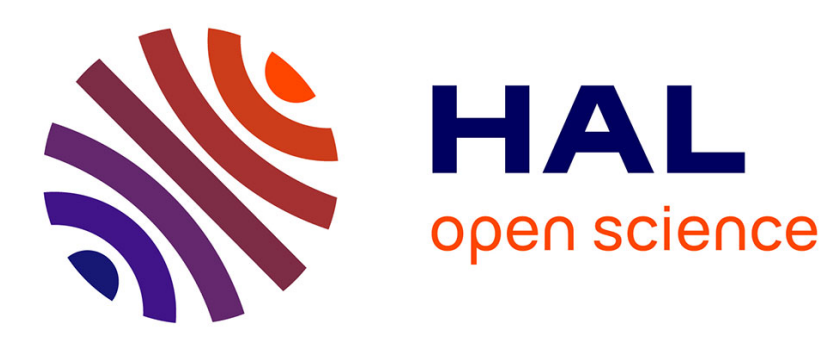

\title{
Low Frequency Internal Friction Induced by Structural Relaxation of Metallic Glasses
}

\author{
V. Belyavsky, O. Bobrov, V. Khonik, A. Kosilov
}

\section{To cite this version:}

V. Belyavsky, O. Bobrov, V. Khonik, A. Kosilov. Low Frequency Internal Friction Induced by Structural Relaxation of Metallic Glasses. Journal de Physique IV Proceedings, 1996, 06 (C8), pp.C8-715C8-718. 10.1051/jp4:19968156 . jpa-00254590

\section{HAL Id: jpa-00254590 https://hal.science/jpa-00254590}

Submitted on 1 Jan 1996

HAL is a multi-disciplinary open access archive for the deposit and dissemination of scientific research documents, whether they are published or not. The documents may come from teaching and research institutions in France or abroad, or from public or private research centers.
L'archive ouverte pluridisciplinaire HAL, est destinée au dépôt et à la diffusion de documents scientifiques de niveau recherche, publiés ou non, émanant des établissements d'enseignement et de recherche français ou étrangers, des laboratoires publics ou privés. 


\title{
Low Frequency Internal Friction Induced by Structural Relaxation of Metallic Glasses
}

\author{
V.I. Belyavsky, O.P. Bobrov, V.A. Khonik and A.T. Kosilov* \\ Department of General Physics, State Pedagogical University, Lenin Str. 86, 394043 Voronezh, Russia \\ * Department of Metal Physics, State Technical University, Moskosky Pr. 14, 394026 Voronezh, Russia
}

\begin{abstract}
A quantitative model of visco-plastic damping induced by structural relaxation of metallic glasses is developed. The model is shown to be consistent with the experiment.
\end{abstract}

\section{INTRODUCTION}

Metallic glasses (MG) are non-equilibrium structures that causes spontaneous irreversible atomic rearrangements generally known as "structural relaxation". Low frequency internal friction (IF) is highly sensitive to structural relaxation. In spite of the fact that main experimental regularities in this field are well-known [1-5], any acceptable understanding of mechanisms responsible for losses under intensive structural relaxation is still lacking. Several qualitative models [3-6] were proposed. However, it can be stated, that at present any justified quantitative notions about IF in $\mathrm{MG}$ under intensive structural relaxation are absent.

Recently [7-10] we proposed a new mechanism of irreversible structural relaxation in an external stress field. A model of creep which explained main experimental observations was developed on its basis [7-9]. In this paper a model of low frequency IF based on the same structural relaxation mechanism is presented.

\section{STRUCTURAL RELAXATION AND INTERNAL FRICTION KINETICS}

According to Ref. [7-10] structural relaxation is viewed as a set of irreversible uncorrelated elementary atomic rearrangements with distributed activation energies in definite areas of structure - "relaxation centres" (RC). Every rearrangement occurs through two stages. At the stage I a thermoactivated shear with the activation volume $V=v_{0} \gamma_{0}$ is realized, where $v_{0}$ is the volume occupied by atoms which contribute directly to the work of external forces, $\gamma_{0}$ the shear deformation of the volume $v_{0}$. The orientation of this shear is determined by a particular atomic configuration of the volume $v_{0}$ and is independent of external stress orientation. The latter, however, influences the activation energy of the shear. Such atomic configurations can be considered as "retainers" which hold back plastic deformation of the surrounding area. Thermoactivated elimination of a retainer results in immediate co-operative displacement of atoms in the nearest neighbourhood that can be interpreted as the stage II of an elementary shear - the stage of viscous flow in a volume $\Omega$ which includes $v_{0}$. Atomic displacements in the volume $\Omega$ result in local plastic deformation which includes hydrostatic compression and accidentally oriented shear. An averaging of such shears over various volumes $\Omega$ does not lead to a macroscopic deformation. An external stress results in an anisotropy of elementary shears and leads to 
accumulation of macroscopic plastic deformation according to the orientation and magnitude of external stress. There arises a "directed structural relaxation", that is one oriented by external stress.

Let $\mathrm{N}_{0}(\mathrm{E})$ be the initial volume density of RC per unit activation energy interval. Then using the first order kinetic equation it is easy to show $[7,8]$ that after preannealing at a temperature $T$ during time $\tau$ the activation energy spectrum (AES) becomes

$$
\mathrm{N}(\mathrm{E}, \mathrm{T}, \tau)=\mathrm{N}_{0}(\mathrm{E}) \exp \left(-v \tau \exp \left(\frac{-\mathrm{E}}{\mathrm{kT}}\right)\right)=\mathrm{N}_{0}(\mathrm{E}) \Theta(E, T, \tau)
$$

where $E$ is the activation energy for the stage $I, v$ the attempt frequency, $k$ the Boltzman's constant. The function $\Theta(E, T, \tau)$ exists in the interval $0 \leq \Theta \leq 1$ and sharply changes near a particular activation energy $E_{0}$, called the characteristic energy $[7,8]$. This energy which corresponds to the maximal rate of RC density decrease can be defined from the condition

$$
\left(\frac{\partial^{2} \mathrm{~N}}{\partial \mathrm{E} \partial \tau}\right)_{\mathrm{E}=\mathrm{E}_{0}}=0
$$

Taking (2) into account the equation for the characteristic energy can be written as

$$
\mathrm{E}_{0}=\mathrm{k} T \ln \left(v \tau\left(1-\frac{\mathrm{kT}}{\mathrm{N}_{0}} \frac{\partial \mathrm{N}_{0}}{\partial \mathrm{E}}\right)^{-1}\right)
$$

Then the function $\Theta(E, T, \tau)$ can be approximated by the step Heaviside function and the structural relaxation rate will be determined by the rate of $\mathrm{E}_{0}$ increase. At $\mathrm{T}=$ const this rate is decreased in time according to the hyperbolic law: $\partial \mathrm{E}_{0} / \partial \tau=\mathrm{kT} / \tau$.

Consider the case of linear heating. Let a glass be preannealed at $T=T_{0}$ during time $\tau$ then a linear heating at a rate $\alpha$ begins from that time moment on. Then the AES becomes

$$
\mathrm{N}(\mathrm{E}, \mathrm{T}, \mathrm{t})=\mathrm{N}_{0}(\mathrm{E}) \exp \left(-v \tau \exp \left(\frac{-\mathrm{E}}{\mathrm{kT}_{0}}\right)\right) \exp \left(-v \int_{0}^{\mathrm{t}} \exp \left(-\frac{\mathrm{E}}{\mathrm{k}\left(\mathrm{T}_{0}+\alpha \mathrm{x}\right)}\right) \mathrm{dx}\right)
$$

Using (2) and (4) a transcendental equation for the characteristic energy can be obtained:

$$
\frac{1}{\mathrm{~N}_{0}}\left(\frac{\partial \mathrm{N}_{0}}{\partial \mathrm{E}}\right)_{\mathrm{E}=\mathrm{E}_{0}}+\frac{v \tau}{\mathrm{kT}_{0}} \exp \left(-\frac{\mathrm{E}_{0}}{\mathrm{kT}_{0}}\right)+v \int_{0}^{\mathrm{t}} \frac{\exp \left(-\mathrm{E}_{0} / \mathrm{k}\left(\mathrm{T}_{0}+\alpha \mathrm{x}\right)\right)}{\mathrm{k}\left(\mathrm{T}_{0}+\alpha \mathrm{x}\right)} \mathrm{dx}-\frac{1}{\mathrm{k}\left(\mathrm{T}_{0}+\alpha \mathrm{t}\right)}=0 .
$$

This equation was solved numerically under the "quasiflat spectrum" approximation, $\mathrm{N}_{0}(\mathrm{E}) / \mathrm{kT} \gg \partial \mathrm{N}_{0} / \partial \mathrm{E}$, using: $v=10^{13} \mathrm{~s}^{-1}, \mathrm{~T}_{0}=293 \mathrm{~K}, \tau=6$ months, $\alpha=10 \mathrm{~K} / \mathrm{min}$. It was found that at $\mathrm{T} \geq 380 \mathrm{~K}$ the characteristic energy is a linear function of temperature, $\mathrm{E}_{0}=\mathrm{AT}$, where $\mathrm{A}=3.1 \cdot 10^{-3} \mathrm{eV} / \mathrm{K}$. Just as in the isothermal case, structural relaxation rate is determined by the time derivative of the characteristic energy, $\partial \mathrm{E}_{0} / \partial \mathrm{t}=\mathrm{A} \alpha$.

The activation energy of the stage $I$ of an elementary shear is dependent on orientation and magnitude of external stress and can be evaluater as $\mathrm{E}_{0}-\Delta \mathrm{E} \leq \mathrm{E} \leq \mathrm{E}_{0}+\Delta \mathrm{E}$, where $\Delta \mathrm{E}=\gamma_{0} \mathrm{v}_{0} \sigma_{0}, \sigma_{0}$ is the external shear stress amplitude. Taking $\mathrm{v}_{0}$ about the volume per atom $\left(20 \cdot 10^{-30} \mathrm{~m}^{3}\right), \gamma_{0} \approx 1$, the maximal strain amplitude $\propto 10^{-4}$, the shear modulus $\mathrm{G}=60$ $\mathrm{GPa}$, one obtains $\Delta \mathrm{E} \approx 7 \cdot 10^{-4} \mathrm{eV}$. Because activation energy of structural relaxation exceeds $1 \mathrm{eV}$, the characteristic energy can be considered as stress independent.

Structural relaxation in an external stress field results in macroscopic deformation. An expression for the macroscopic plastic deformation tensor $\varepsilon_{\mathrm{ik}}$ was proposed in [10]:

$$
\varepsilon_{\mathrm{ik}}=\left(-\frac{1}{3} \varepsilon_{11}^{(0)} \delta_{\mathrm{ik}}+\mathrm{c}^{(1)} \sigma_{\mathrm{il}} \delta_{\mathrm{ik}}+2 \mathrm{c}^{(2)} \sigma_{\mathrm{ik}}\right) \Omega \int \mathrm{N}_{0}\left(\mathrm{E}_{0}\right) \mathrm{dE}_{0},
$$


where $\varepsilon_{\mathrm{il}}^{(0)}$ is the spur of the average (over various $\Omega$ ) local plastic deformation tensor, $\delta_{\mathrm{ik}}$ the Kronecker delta, $\sigma_{i k}$ the external stress tensor, $c^{(1)}$ and $c^{(2)}$ the unknown structural parameters. The integral in Eq.(6) is calculated in the limits corresponding to the $\mathrm{E}_{0}$ position in the beginning and at the end of the experiment. Then, designating $C=2 c_{0}^{(2)}$, the macroscopic strain rate under pure harmonic shear, $\sigma_{\mathrm{ik}}=\sigma_{12}=\sigma_{0} \cos \omega t$, can be written as

$$
\dot{\varepsilon}=\sigma \mathrm{N}_{0}\left(\mathrm{E}_{0}\right) \Omega \mathrm{CE} \dot{\mathrm{E}}_{0} \text {. }
$$

Under linear heating elastic energy losses over a vibration period are equal to $\Delta \mathrm{W}=\pi \sigma_{0}^{2} \mathrm{~N}_{0} \Omega \mathrm{C} \dot{E}_{0} / \omega$. Then the IF becomes

$$
\mathrm{Q}^{-1}=\Delta \mathrm{W} / 2 \pi \mathrm{W}=\mathrm{N}_{0}^{*}\left(\mathrm{E}_{0}\right) \dot{\mathrm{E}}_{0} / \omega=\mathrm{N}_{0}^{*}\left(\mathrm{E}_{0}\right) \mathrm{A} \alpha / \omega,
$$

where $\mathrm{N}_{0}^{*}=\mathrm{N}_{0} \Omega \mathrm{CG}$ is an unknown temperature dependent function of $\mathrm{E}_{0}$.

Under isothermal conditions, after preannealing during time $\tau, \dot{E}_{0}=\mathrm{kT} /(\mathrm{t}+\tau)$. Then, taking Eq.(6) into account, the strain rate is

$$
\dot{\varepsilon}=\sigma_{0} \mathrm{kTN} N_{0}^{*}\left(\mathrm{E}_{0}\right) \cos \omega \mathrm{t} /(\mathrm{t}+\tau) \text {. }
$$

Energy losses per cycle are equal $\Delta \mathrm{W}=\pi \sigma_{0}^{2} \mathrm{~N}_{0} \Omega \mathrm{CkT} / \omega(\mathrm{t}+\tau)$. Then the IF isothermal kinetics is described by the equation

$$
\mathrm{Q}^{-1}=\mathrm{N}_{0}^{*}\left(\mathrm{E}_{0}\right) \dot{\mathrm{E}}_{0} / \omega=\mathrm{kTN}_{0}^{*}\left(\mathrm{E}_{0}\right) / \omega(\mathrm{t}+\tau)
$$

where the characteristic energy is time dependent according to the logarithmic law:

$$
\mathrm{E}_{0}=k \mathrm{k} \ln v(\mathrm{t}+\tau) \text {. }
$$

Eqs. (7) and (9) show that both under isothermal conditions and linear heating the IF is expressed via $\dot{\mathrm{E}}_{0}$. The latter defines the structural relaxation rate. Therefore, one must conclude that IF is also determined by the structural relaxation rate.

Finally, the effective preannealing time $\tau$ in Eq.(9) should be evaluated. If a sample is heated at some rate to the temperature of subsequent isothermal testing then the IF values calculated with help of Eq.(7) and Eq.(9) at $t=0$ should coincide. So, one can state that heating at a finite rate $\alpha$ to a particular temperature is equivalent to instantaneous warming up to the same temperature and subsequent annealing during time $\tau=\mathrm{kT} / \alpha \mathrm{A}$.

\section{EXPERIMENTAL VERIFICATION}

In order to check the model we carried out IF measurements of $\mathrm{Co}_{70} \mathrm{Fe}_{5} \mathrm{Si}_{15} \mathrm{~B}_{10} \mathrm{MG}$. Samples for testing were prepared by cutting the ribbon $(35-40 \mathrm{mcm}$ thick) into strips $40-50$ mcm width and 8-10 $\mathrm{mm}$ length using a special cutting-out press. Then a sample was etched in the nitric acid in order to remove surface layer disturbed by cutting and was cemented into a conventional torsion micropendulum using special glue. Sample gauge length after cementing was 2-3 mm. IF was measured in the free decay mode at the accuracy of $10 \%$ at $\mathrm{Q}^{-1} \sim 5 \cdot 10^{-2}$ and $\sim 1 \%$ at $\mathrm{Q}^{-1} \sim 10^{-3}$. All measurements were carried out in vacuum $10^{-1} \mathrm{~Pa}$ under the fixed strain amplitude. For the model analysis the background damping $\left(Q_{\text {rel }}^{-1}\right)$ characteristic of relaxed amorphous state was subtracted from the measured IF $\left(Q_{\text {mea }}^{-1}\right)$ level: $\mathrm{Q}^{-1}(\mathrm{~T}, \mathrm{t})=\mathrm{Q}_{\text {mea }}^{-1}(\mathrm{~T}, \mathrm{t})-\mathrm{Q}_{\mathrm{rel}}^{-1}(\mathrm{~T}) \cdot \mathrm{Q}_{\mathrm{rel}}^{-1}(\mathrm{~T})$ was determined after preannealing at $703 \mathrm{~K}$ during $30 \mathrm{~min}$. The choice of this treatment was determined, on the one hand, by the quest to achieve the maximum relaxed state and, on the other hand, to avoid crystallization.

It follows from Eq.(7) that the product $Q^{-1} \omega$ at a fixed temperature must be a linear function of the heating rate. The corresponding experimental plot is shown in Fig.1. Indeed, at any fixed temperature, which corresponds to an isothermal cut of $\mathrm{Q}^{-1}(\mathrm{~T})$ curves, $\mathrm{Q}^{-1} \omega$ increases linearly with the heating rate.

According to Eq.(9) the IF isothermal time dependence should straighten in the $\mathrm{Q}^{-1}(\mathrm{t})-\mathrm{N}_{0}^{*}(\mathrm{t}) /(\mathrm{t}+\tau)$ co-ordinates with the angle coefficient equal to $\mathrm{kT} / \omega$. The function 


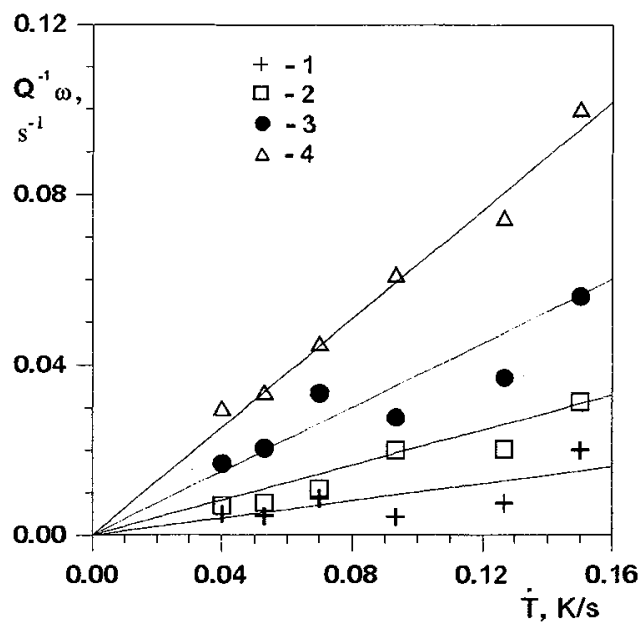

Figure 1: $Q^{-1} \omega$ versus heating rate dependences: 1 - $373 \mathrm{~K} ; 2$ - $473 \mathrm{~K} ; 3$ - $573 \mathrm{~K} ; 4$ - $673 \mathrm{~K}$. Solid lines correspond to average angle coefficients of lines drawn from the origin to every experimental point at $\mathrm{T}=\mathrm{const}$.

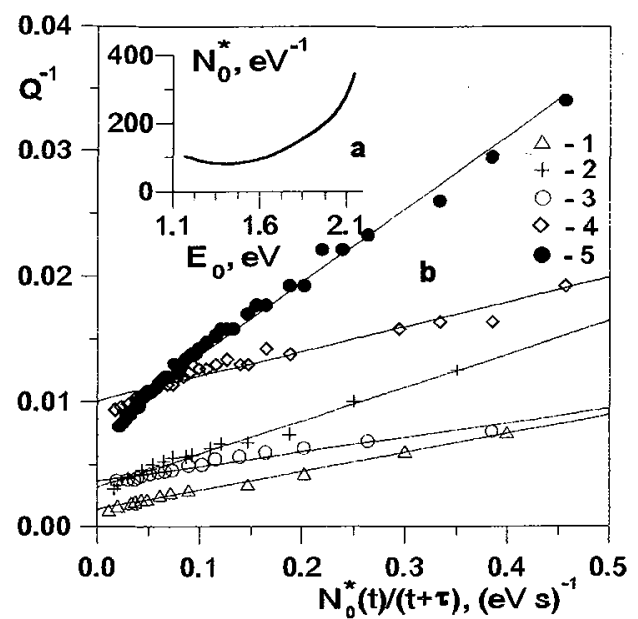

Figure 2: $a$ : the $N_{0}^{*}\left(E_{0}\right)$ dependence. $b$ : replotting of IF isothermal kinetics in the straightening co-ordinates. 1 - $473 \mathrm{~K}\left(3.0 \mathrm{~s}^{-1}\right) ; 2$ $573 \mathrm{~K}\left(2.1 \mathrm{~s} \mathrm{~s}^{-1}\right) ; 3-573 \mathrm{~K}\left(3.9 \mathrm{~s}^{-1}\right) ; 4-623 \mathrm{~K}(2.4$ $\left.\mathrm{s}^{-1}\right) ; 5-623 \mathrm{~K}\left(1.6 \mathrm{~s}^{-1}\right)$

$N^{*}(t)$ was calculated using anisothermal $Q^{-1}(T)$ data. To do this the temperature dependence $\mathrm{N}_{0}^{*}(\mathrm{~T})$ according Eq.(7) was calculated. The latter with the help of calculated $\mathrm{E}_{0}(\mathrm{~T})$ dependence was transformed into $\mathrm{N}_{0}^{*}\left(\mathrm{E}_{0}\right)$ relationship shown in Fig.2,a. Finally, using Eq.(10) a $\mathrm{N}_{0}^{*}$ value was assigned to a particular time moment. The results of $\mathrm{Q}^{-1}(\mathrm{t})$ replotting in straightening co-ordinates are shown in Fig.2,b. Solid lines are drawn with angle coefficients equal to $\mathrm{kT} / \omega$. It is seen that experimental data are in good agreement with model calculations.

\section{Acknowledgements}

The financial support of the ICIFUAS-11 Organising Committee is greatly acknowledged. This work was supported in part by the Russian Foundation of Basic Research under grant N95-02-03970.

\section{References}

[1] Morito N., Mater.Sci.Eng. 60 (1983) 261-268.

[2] Morito N., Egami T., J.Non-Cryst.Solids 61-62 (1984) 973-978.

[3] Morito N., Egami T., Acta Metall. 32 (1984) 603-613.

[4] Deng D., Argon A.S., Acta Metall. 34 (1986) 2025-2038.

[5] Chen H.S., Morito N. J.Non-Cryst.Solids 72 (1985) 287-299.

[6] Van den Beukel A., Phys.Stat.Sol.A 129 (1992) 49-57.

[7] Kosilov A.T., Khonik V.A., Izv.RAN. Ser.Fiz. 33 (1993) 3393-3399.

[8] Khonik V.A., Kosilov A.T., Mikhailov V.A., J.Non-Cryst.Solids 192-193 (1995) 420-423.

[9] Bobrov O.P., Kosilov A.T., Mikhailov V.A., Khonik V.A. Izv.RAN. Ser.Fiz., 1996, in press.

[10] Belyavskii V.A., Bobrov O.P., Kosilov A.T., Khonik V.A., Fiz.Tverd.Tela 38 (1996) 30-40. 